\title{
HOUSEHOLD SECONDARY ATTACK RATE OF COVID-19 AND ITS ASSOCIATED RISK FACTORS IN WESTERN UTTAR PRADESH: A CROSS SECTIONAL STUDY
}

\section{Community Medicine}

Harivansh Chopra Professor, Department of Community Medicine, L. L. R. M Medical College, Meerut, UP

Tanveer Bano

Gargi Pandey*
Professor \& Head, Department of Community Medicine, L. L. R. M Medical College, Meerut, U.P

Junior Resident, Department of Community Medicine, L. L. R. M Medical College,

Meerut. *Corresponding Author

\section{ABSTRACT}

Coronavirus disease was declared pandemic by World health organization in March 2020. Since then many prediction based on scientific models regarding its transmission were done. This cross sectional study was done on household contacts of 100 COVID-19 recovered and discharged cases. Secondary attack rate among family members was found out to be $27.41 \%$. A significant association was found in occurrence of secondary cases in relation to joint family, overcrowding, non use of facemask and infrequent hand washing

\section{KEYWORDS}

COVID-19, Secondary Attack Rate, Household Transmission

\section{INTRODUCTION}

COVID-19 first case was diagnosed from Wuhan, China in December 2019. Soon Coronavirus 2019 (COVID 19) became pandemic. Worldwide great efforts are been taken to find out the factors associated with the transmission of disease and to stop further spread of disease ${ }^{[1]}$. One of those efforts in India included nationwide lockdown on March 24 2020. But it failed to stop progress of COVID19 cases in India ${ }^{[2]}$. Few early studies done for contact tracing showed risk of household transmission from COVID- 19 infected cases to be highest ${ }^{[1]}$.

At present disease transmission is predicted more at population level through mathematical model while household transmissibility is something less researched upon ${ }^{[3]}$.

\section{AIMS \& OBJECTIVES}

1) To find out secondary attack rate among household contacts of COVID 19 index cases.

2) To find out the association of transmission of risk factors among contacts in family

\section{MATERIAL \& METHODS}

This cross sectional study was carried out among 100 discharged index cases selected randomly out of total 588 patients admitted at Lala Lajpat Rai Medical College during the time period of March 2020 to June 2020. Telephonic interview of index cases and their family members was taken on pre-designed pretested validated questionnaire. There were 434 individual were in families of 100 discharged cases. Any family member becoming positive with RT-PCR within 14 days of onset of symptoms of index cases were taken as secondary cases and secondary attack rate was calculated as following:

Secondary attack rate $=$

no. of contacts developing COVID-19 $\times 100$

Total number of susceptible

All positive contacts were quarantined or hospitalized as per their degree of illness as per guideline of Ministry of health, Uttar Pradesh government.

\section{ETHICALAPPROVAL}

This study was approved by Institute's ethical committee

\section{CONSENT}

Each participant was interviewed after taking verbal informed consent

\section{STATISTICALANALYSIS}

Data collected was entered and analysed by Epi Info 7.2.3.1 software. Univariate analysis for association between occurrence of secondary cases and various risk factors was assessed using chi square test and independent predictors of secondary attack rate were assessed using multivariate logistic regression; $\mathrm{p}$ value of $<0.05$ was taken as significant.

\section{RESULTS}

Out of 434 household contacts there were 119 secondary cases that represent a secondary attack rate of $27.41 \%$.

In $46 \%$ of families no secondary cases occurred.

Risk factors associated with the secondary cases of COVID -19 are shown in

Table 1.

Table 1: Association Of Risk Factors With Confirmed Secondary Covid-19 Cases In Household Contact

\begin{tabular}{|l|l|l|l|l|l|}
\hline Characteristics & $\begin{array}{l}\text { Second-ary } \\
\text { cases } \\
(\%)\end{array}$ & $\begin{array}{l}\text { No Secondary- } \\
\text { y cases } \\
(\%)\end{array}$ & Total & $\begin{array}{l}\text { Chi } \\
\text { square }\end{array}$ & P value \\
\hline Age Group(yrs) & & & & & \\
\hline $0-15$ & $3(2.52)$ & $49(15.56)$ & 52 & & \\
\hline $16-30$ & $12(10.08)$ & $36(11.43)$ & 48 & 21.70 & 0.00 \\
\hline $31-45$ & $36(30.25)$ & $74(23.49)$ & 110 & & \\
\hline $46-60$ & $43(36.14)$ & $70(22.22)$ & 113 & & \\
\hline$>60$ & $25(21.01)$ & $86(27.30)$ & 111 & & \\
\hline Total & $119(100.0)$ & $315(100.0)$ & 434 & & \\
\hline Gen-der & & & & & \\
\hline Male & $63(52.94)$ & $140(44.44)$ & 203 & & \\
\hline Female & $56(47.06)$ & $175(55.56)$ & 231 & 2.17 & 0.140 \\
\hline Total & $119(100.0)$ & $315(100.00)$ & 434 & & \\
\hline $\begin{array}{l}\text { No. of person/ } \\
\text { room }\end{array}$ & & & & & \\
\hline$<=2$ & $7(5.88)$ & $16(51.11)$ & 168 & & \\
\hline$>2$ & $112(94.12)$ & $154(48.89)$ & 266 & 72.58 & 0.00 \\
\hline Total & $119(100.0)$ & $315(100.0)$ & 434 & & \\
\hline Type of family & & & & & \\
\hline Nuclea-r & $16(13.44)$ & $19(6.03)$ & 35 & & \\
\hline Joint & $81(68.7)$ & $69(21.91)$ & 150 & 53.38 & 0.00 \\
\hline Extended & $22(18.49)$ & $227(72.06)$ & 249 & & \\
\hline Total & $119(100.0)$ & $315(100.0)$ & 434 & & \\
\hline Hand Washi-ng & & & & & \\
\hline Freque-nt & $8(6.72)$ & $163(51.75)$ & 171 & & \\
\hline In-frequent & $111(93.28)$ & $152(48.25)$ & 263 & 71.45 & 0.00 \\
\hline Total & $119(100.0)$ & $315(100.0)$ & 434 & & \\
\hline $\begin{array}{l}\text { Use of Face } \\
\text { mask }\end{array}$ & & & & & \\
\hline Present & $7(5.88)$ & $221(70.16)$ & 228 & & \\
\hline Absent & $112(94.12)$ & $94(29.84)$ & 213 & 140.54 & 0.00 \\
\hline Total & $119(100.0)$ & $315(100.00)$ & 434 & & \\
\hline $\begin{array}{l}\text { Stay with } \\
\text { family memb-er } \\
\text { in one go }\end{array}$ & & & & & \\
\hline$<=15 m i n$ & $38(31.93)$ & $131(41.59)$ & 169 & 2.99 & 0.084 \\
\hline$>15$ min & $81(68.07)$ & $184(58.41)$ & 265 & & \\
\hline Total & $119(100.0)$ & $315(100.00)$ & 434 & & \\
\hline & & & & \\
\hline
\end{tabular}


A statistically significant association found of secondary attack rate in relation to age where it was found maximum in 46-60 years of age followed by $31-45$ years of age and least in $0-15$ years of age. Similarly statistically significant association also found between secondary attack rate and overcrowding, lack of hand washing and lack of use of facemask as in households who were practicing frequent hand washing and use of facemask secondary cases were only $6.72 \%$ and $5.88 \%$ respectively.

$68.07 \%$ of secondary cases were occurring when duration of contact with primary case was more than 15 minutes but it was not statistically significant

Multivariate logistic regression for understanding relative contribution of various risk factors is shown in table 2 and factors found having significant association in chi square test were included.

Table 2: Multivariate Logistic Regression Analysis Of Association Of Risk Factors With Confirmed Secondary COVID-19 Cases In Household Contact

\begin{tabular}{|l|l|l|l|l|}
\hline Risk factors & Odds ratio & $95 \%$ C.I & C.I & P \\
\hline Age group & 0.7287 & 0.45 & 1.17 & 0.11 \\
\hline Hand washing & 0.0199 & 0.01 & 0.07 & 0.00 \\
\hline Overcrowding (yes/no) & 0.1608 & 0.05 & 0.52 & 0.00 \\
\hline $\begin{array}{l}\text { Type of family (nuclear/extended } \\
\text { joint) }\end{array}$ & 11.84 & 5.51 & 25.42 & 0.00 \\
\hline Use of facemask (present/absent) & 0.0125 & 0.00 & 0.04 & 0.00 \\
\hline
\end{tabular}

As seen in table 2 type of family (joint family) was detrimental in occurrence of secondary cases with or $=11.83$ and it was found to be statistically significant $(\mathrm{p}=0.00)$.

While odds of frequent hand washing, absence of overcrowding and use of face mask were lower in secondary cases and were found to be statistically significant $(\mathrm{p}<0.05)$. These might indicate that frequent hand washing, absence of overcrowding and use of facemask were protective factors against secondary transmission of sars-cov-2 in family members.

\section{DISCUSSION:}

In this study transmission of SARS cov-2 among family members was not very common and secondary attack rate were lower than 53\% reported by Grijalva and Rolfes $(2020){ }^{[4]}$ which was done in west part of world where hugging and kissing is normal form of greeting as compared to India where Namaste or other forms of greeting are commonly used. Also as there was no quarantine of contacts of index case hence some infections might have originated outside the household leading to higher secondary attack rate. In an another study by Jing et al ${ }^{[3]}$ secondary attack rate was found out to be $17.1 \%$ when household contacts were defined on the basis of residential address as in our study, which was lower than our estimation of $27.41 \%$ which could be due to the early action taken by Chinese government in isolating and identifying the cases as compared to our Indian settings where delay in increase of test was present

Also age of secondary cases was important risk factor which is similar to Pena et al ${ }^{[5]}$.

Although occurrence of secondary cases was $68.07 \%$ in contacts spending more than 15 minutes with the primary case but it was not significant, it might show that in presence of other protective factors which includes facemask and frequent hand washing duration of stay is not important.

Other factors found to be important were frequent hand washing, presence of overcrowding, and type of family and use of facemask. We could not find any study showing relationship between secondary attack rate of COVID-19 and overcrowding, frequent hand washing and use of facemask.

\section{CONCLUSION:}

In present study Secondary attack rate was $27.41 \%$ which shows that disease is less infectious than other respiratory infection but as disease has high mortality in vulnerable group therefore we should practice frequent hand washing, use of facemask and maintain distance to stop its transmission. Early identification of COVID-19 cases and their isolation could further decrease the occurrence of Secondary attack rate. More studies are needed to find out the relationship of significant risk factors found in this study with secondary attack rate.
RECOMMENDATION:

This study brings out the emphasis on preventive measures of MDH i.e. masking (face), maintaining distance (physical) and hand washing(frequent). They will definitely make a dent in reducing transmission of SARS-CoV-2 in household as well as community.

LIMITATION OF THE STUDY:

As we could include 100 patients, more studies are required to validate the findings

\section{REFERENCES:}

1) Shah, K . Saxena, D and Mavalankar, D., 2020. Secondary attack rate of COVID-19 i household contacts: a systematic review. QJM: An International Journal of Medicine

2. Balsari S, Sange M, Udwadia Z COVID-19 care in India: the course to self-reliance. The Lancet Global Health. 2020;8(11):e1359-e1360.

3) 3. Jing Q, Liu M, Zhang Z, Fang L, Yuan J, Zhang A et al. Household secondary attack rate of COVID-19 and associated determinants in Guangzhou, China: a retrospective cohort study. The Lancet Infectious Diseases. 2020;20(10):1141-1150.

4) Grijalva C, Rolfes M.,Zhu Y, Mclean H., Hanson K., Belongia E, Halasa N., Kim A Transmission of SARS Co-V-2 infection in households- Tenessee and Wisconsin, AprilSeptember 2020.Morbidity and Mortality Weekly Report

5) Pena A, Vidal S, Ferrer N,COVID-19 Secondary attack rate and risk factors in households contacts in Castellon(Spain):Preliminary report. Rev Enf Emerg 2020;19(2):64-70 